Article

\title{
A Low Temperature Detoxification Method for Treatment of Chrysotile-Containing Waste Roofing Slate
}

\author{
Hwanju Jo *, Young Nam Jang and Jung Hyun Jo \\ Center for Carbon Mineralization, Climate Change Mitigation and Sustainability Division, Korea Institute of \\ Geoscience and Mineral Resources, 124, Gwahak-ro, Yuseong-gu, Daejeon 34132, Korea; \\ crystal@kigam.re.kr (Y.N.J.); liketbc@nate.com (J.H.J.) \\ * Correspondence: chohwanju@kigam.re.kr; Tel.: +82-42-868-3473
}

Received: 14 July 2017; Accepted: 8 August 2017; Published: 10 August 2017

\begin{abstract}
In this study, we evaluated a two-step process for detoxification of waste roofing slate, involving cement hydrate removal and low temperature detoxification using oxalic acid. These treatments were conducted on raw material and intermediate product, respectively. Cement hydrate removal effectively eliminated most Ca-containing cement hydrate components from the raw material under the following conditions: $\mathrm{HCl}$ to solid ratio: $0.456 \mathrm{~g} / \mathrm{g}$, reaction time: $2 \mathrm{~h}$, and solid to liquid ratio: $0.124 \mathrm{~g} / \mathrm{mL}$. Following low temperature $\left(\sim 100^{\circ} \mathrm{C}\right)$ detoxification of intermediate product obtained after cement hydrate removal, chrysotile in waste roofing slate was effectively transformed to $\mathrm{Mg}$-oxalate under conditions of oxalic acid to solid ratio of $>0.67 \mathrm{~g} / \mathrm{g}$.
\end{abstract}

Keywords: asbestos; detoxification; oxalic acid; Mg oxalate

\section{Introduction}

Asbestos-containing materials (ACMs) have been widely used since 4000 B.C. for various applications, due to their high mechanical strength and low heat conductivity [1]. Asbestos includes two groups of commonly occurring silicate minerals: the serpentine group (e.g., chrysotile) and the amphibole group (e.g., actinolite, amosite, anthophyllite, crocidolite, and tremolite). Of these minerals, chrysotile is the most widely used ( $90 \%$ of world production) [2]. It consists of alternating silicate tetrahedral sheets and brucite $\left(\mathrm{Mg}(\mathrm{OH})_{2}\right)$ octahedral sheets and has a cylindrical structure due to structural discordances in mineral lattices, resulting from the substitution of $\mathrm{Si}^{4+}$ to $\mathrm{Al}^{3+}$ and $\mathrm{Mg}^{2+}$ to $\mathrm{Fe}^{2+}$ or $\mathrm{Al}^{3+}$, respectively [3].

Asbestos is well known to cause asbestosis, lung cancer, and pleural mesothelioma, and all types of asbestos have been classified as carcinogenic by the International Agency of Research on Cancer [4]. Due to its severe carcinogenicity, the use of asbestos is nowadays strongly prohibited in many developed countries. South Korea has likewise prohibited the use, transport, modification, and unauthorized reclamation of asbestos and asbestos-containing materials since 2003.

Asbestos production in South Korea began in the 1930s due to high demand for use in Japanese military supplies during World War II. Most of the asbestos produced in Korea until 1945 was therefore exported to Japan. Between 1945 and the 1990s, approximately 145,533 tons of asbestos were produced. Additionally, about 1,227,720 cumulative tons of asbestos have been imported into the country since 1976. Up to $96 \%$ of asbestos imported in the 1970 s was used in roof slate, while $82 \%$ of asbestos imported in the 1990s was used for interior insulation and roof slate [5]. Chrysotile was the most commonly used for roof slate manufacturing in South Korea.

Since the harmful nature of asbestos became known, several asbestos detoxification methods have been proposed. One proposed that thermal decomposition is a reliable detoxification method. 
Asbestos minerals can be decomposed by dehydroxylation and recrystallization at temperatures that depend on mineral type [2]. Thermal decomposition of chrysotile theoretically follows the reaction path given below [6]:

$$
\begin{gathered}
\mathrm{Mg}_{3} \mathrm{Si}_{2} \mathrm{O}_{5}(\mathrm{OH})_{4} \text { (chrysotile) } \rightarrow \mathrm{Mg}_{3} \mathrm{Si}_{2} \mathrm{O}_{7} \text { (metachrysotile) }+2 \mathrm{H}_{2} \mathrm{O} \text { at } 500{ }^{\circ} \mathrm{C} \\
\mathrm{Mg}_{3} \mathrm{Si}_{2} \mathrm{O}_{7} \text { (metachrysotile) } \rightarrow \mathrm{Mg}_{2} \mathrm{SiO}_{4} \text { (forsterite) }+\mathrm{MgSiO}_{3} \text { (enstatite) at } 750{ }^{\circ} \mathrm{C}
\end{gathered}
$$

This reaction path indicates that chrysotile decomposes into forsterite and enstatite at $750{ }^{\circ} \mathrm{C}$; however, Gualtieri and Tartaglia [6] observed complete recrystallization of chrysotile at $1100{ }^{\circ} \mathrm{C}$. It is thus believed that temperatures $>1100{ }^{\circ} \mathrm{C}$ are needed for chrysotile detoxification via thermal decomposition. Thermal asbestos detoxification treatments in a water vapor atmosphere [7] and using microwaves [8-10] and microwave air plasma [11] have also been proposed. Kozawa et al. [7] showed that chrysotile was decomposed by heat treatment at $800 \mathrm{C}$ in a water vapor atmosphere; the atmosphere also reduced the temperature of chrysotile decomposition. Leonelli et al. [9] conducted microwave treatment at a frequency of $2.45 \mathrm{GHz}$ for $13 \mathrm{~min}$ and $25 \mathrm{~min}$. After treatment, no fibrous asbestos was observed. Horikoshi et al. [10] reported that microwave treatment can effectively decompose asbestos at temperatures lower than those in conventional thermal treatment via rapid heating of the interior of the material. However, thermal treatment requires vast amounts of energy for decomposition or melting of asbestos, due to the material's high heat resistance.

Chemical detoxification methods using $\mathrm{H}_{2} \mathrm{SO}_{4}$ [12], $\mathrm{FSO}_{3} \mathrm{H}$ [13], $\mathrm{CHClF}_{2}$-decomposed acidic gas [14], re-used supernatant from fly ash treatment [15], and $\mathrm{H}_{2} \mathrm{C}_{2} \mathrm{O}_{4}$ [16-18] could also effectively decompose asbestos materials. Strong acids, such as sulfuric acid $\left(\mathrm{H}_{2} \mathrm{SO}_{4}\right)$, hydrochloric acid ( $\left.\mathrm{HCl}\right)$, and hydrofluoric acid (HF), have been extensively investigated as decomposition agents for asbestos detoxification treatments. Nam et al. [12] reported that thermochemical treatment using $5 \mathrm{~N}$ recycled sulfuric acid $\left(\mathrm{H}_{2} \mathrm{SO}_{4}\right)$ at $100{ }^{\circ} \mathrm{C}$ could convert asbestos-containing material into non-fibrous materials. Sugama et al. [13] investigated the decomposition of chrysotile using fluorosulfonic acid ( $\left.\mathrm{FSO}_{3} \mathrm{H}\right)$. In an aqueous medium, $\mathrm{FSO}_{3} \mathrm{H}$ converts to $\mathrm{H}_{2} \mathrm{SO}_{4}$ and $\mathrm{HF}$, which are strong acids. As a result, chrysotile was decomposed into $\mathrm{H}_{2} \mathrm{SiF}_{6}$ and $\mathrm{MgF}_{2}$. Yanagisawa et al. [14] investigated decomposition of asbestos by $\mathrm{CHClF}_{2}$-decomposed acidic gas $\left(\mathrm{HF}\right.$ and $\mathrm{HCl}$ ), generated by reaction with $800{ }^{\circ} \mathrm{C}$ heated steam. In the study, chrysotile was fully decomposed into sellaite $\left(\mathrm{MgF}_{2}\right)$ and magnesium silicofluoride $\left(\mathrm{MgSiF}_{6}\right)$ by reaction with the acidic gas at $150{ }^{\circ} \mathrm{C}$ for $30 \mathrm{~min}$. Tabata et al. [16] proposed an asbestos decomposition method using recycled supernatant obtained from fly ash treatment with sulfur, $\mathrm{Ca}(\mathrm{OH})_{2}$, and water at $0.6 \mathrm{MPa}$ at $160{ }^{\circ} \mathrm{C}$ for $1-2 \mathrm{~h}$. The supernatant was mixed with asbestos in a ball mill at room temperature. After mixing, more than $99.9 \%$ of asbestos was decomposed.

Decomposition of asbestos using oxalic acid $\left(\mathrm{H}_{2} \mathrm{C}_{2} \mathrm{O}_{4}\right)$ has also been extensively investigated. Turci et al. [16] used oxalic acid treatment with a cup-horn ultrasound reactor $(19.2 \mathrm{kHz})$ to detoxify chrysotile asbestos. After treatment, suspended asbestos fiber was fully detoxified to amorphous debris and very short harmless antigorite fibrils. Rozalen and Huertas [17] compared the effects of nitric acid $\left(\mathrm{HNO}_{3}\right)$, sulfuric acid $\left(\mathrm{H}_{2} \mathrm{SO}_{4}\right)$, and oxalic acid $\left(\mathrm{H}_{2} \mathrm{C}_{2} \mathrm{O}_{4}\right)$ on leaching of chrysotile. It was shown that, of the three, oxalic acid has the highest leaching and destruction efficiency. Valouma et al. [18] investigated combined chrysotile asbestos detoxification methods using various combinations of oxalic acid, tetraethoxysilane (TEOS) $\left(\mathrm{SiH}_{20} \mathrm{C}_{8} \mathrm{O}_{4}\right)$, and pure water glass. The proposed detoxification methods decomposed asbestos effectively and produced amorphous silica and glushinskite $\left(\mathrm{MgC}_{2} \mathrm{O}_{4} \cdot 2 \mathrm{H}_{2} \mathrm{O}\right)$.

In this study, we investigated an asbestos detoxification method using hydrochloric acid $(\mathrm{HCl})$ and oxalic acid $\left(\mathrm{H}_{2} \mathrm{C}_{2} \mathrm{O}_{4}\right)$ to transform asbestos-containing roofing slate to a non-toxic product. The acid treatment process consisted of two steps: (1) removal of cement hydrates using $\mathrm{HCl}$ and (2) low temperature $\left(\sim 100{ }^{\circ} \mathrm{C}\right)$ detoxification using $\mathrm{H}_{2} \mathrm{C}_{2} \mathrm{O}_{4}$. It is distinguishable that the proposed treatment process using clearly low temperature $\left(\sim 100^{\circ} \mathrm{C}\right)$ and simpler reaction path than previous studies. The detoxification efficiency of the proposed treatment process was investigated under various experimental conditions (additive concentration, solid to luquid ratio, temperature, and reaction time). 


\section{Materials and Methods}

Chrysotile and waste roofing slate were collected from a serpentine mine and an abandoned house in South Korea, respectively. The samples were then crushed in a rod mill for $18 \mathrm{~h}$ and sieved using mesh size \#200 to obtain a particle size of $<0.075 \mathrm{~mm}$. The chrysotile powder (<\#200) was used directly for a low temperature detoxification test. The waste roofing slate powder was used first for the cement hydrate removal test, then for the low temperature detoxification test. The chemical composition of chrysotile and waste roofing slate was determined through Inductively Coupled Plasma Atomic Emission Spectroscopy (ICP-AES, 5300DV, PerkinElmer Inc., Waltham, MA, USA) (Table 1). Hydrochloric acid ( $\mathrm{HCl}, \mathrm{OCI}$ company Ltd., Seoul, Korea) and oxalic acid dihydrate $\left(\mathrm{H}_{2} \mathrm{C}_{2} \mathrm{O}_{4} \cdot 2 \mathrm{H}_{2} \mathrm{O}\right.$, OCI corporation) solutions were used as solvents for the cement hydrate removal test and low temperature detoxification test, respectively (Figure 1).

Table 1. Chemical composition of chrysotile and waste roofing slate.

\begin{tabular}{ccccccccc}
\hline \multirow{2}{*}{ Material } & \multicolumn{7}{c}{ Chemical Composition (wt \%) } \\
\cline { 2 - 9 } & $\mathbf{S i O}_{\mathbf{2}}$ & $\mathbf{A l}_{\mathbf{2}} \mathbf{O}_{\mathbf{3}}$ & $\mathbf{F e}_{\mathbf{2}} \mathbf{O}_{\mathbf{3}}$ & $\mathbf{C a O}$ & $\mathbf{M g O}$ & $\mathbf{K}_{\mathbf{2}} \mathbf{O}$ & $\mathbf{N a}_{\mathbf{2}} \mathbf{O}$ & $\mathbf{M n O}$ \\
\hline Chrysotile & 26.9 & 0.34 & 31.7 & n.d. ${ }^{1}$ & 24.9 & n.d. & 1.90 & 0.44 \\
Waste Roofing Slate & 18.7 & 4.44 & 3.60 & 35.1 & 6.77 & 0.28 & 0.11 & 0.07 \\
\hline
\end{tabular}

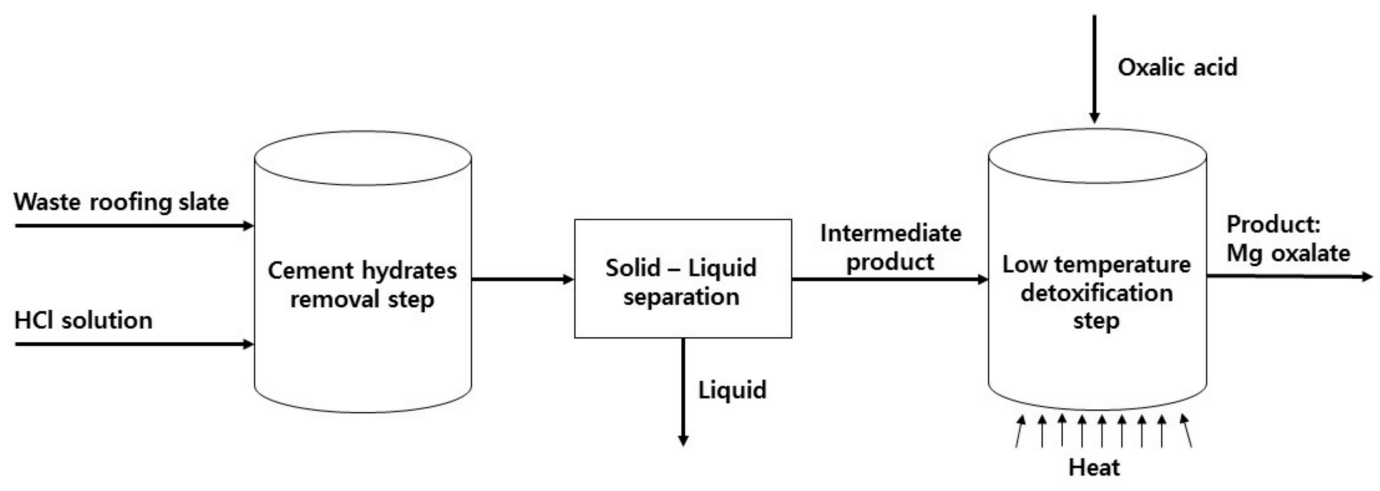

Figure 1. Schematic diagram of process route used in this study.

The low temperature detoxification test was performed using chrysotile to verify the effectiveness of the proposed reaction. The powder chrysotile was placed in a $100 \mathrm{~mL}$ stainless steel reactor and mixed with a solution of oxalic acid (Table 2). The mixture was heated using a hot plate until fully dried. After the detoxification test, solid particles were collected for XRD and FE-SEM analyses to determine the detoxification of chrysotile.

Table 2. Experiment condition of low temperature detoxification test.

\begin{tabular}{cccccccc}
\hline No. & $\begin{array}{c}\text { Chrysotile } \\
\mathbf{( g )}\end{array}$ & $\begin{array}{c}\text { Oxalic } \\
\text { Acid }(\mathbf{g})\end{array}$ & $\begin{array}{c}\text { Water } \\
\mathbf{( m L )}\end{array}$ & $\begin{array}{c}\text { Solid to Oxalic } \\
\text { Acid Ratio } \mathbf{( g / g )}\end{array}$ & $\begin{array}{c}\text { Hot } \\
\text { Platemperature } \\
\left.\mathbf{(}{ }^{\circ} \mathbf{C}\right)\end{array}$ & $\begin{array}{c}\text { Reaction } \\
\text { Time } \\
(\mathbf{m i n})\end{array}$ & $\begin{array}{c}\text { Stirring } \\
\text { Rate } \\
(\mathbf{r p m})\end{array}$ \\
\hline CDT-1 & 3 & 3.0 & 30 & 1.0 & 120 & 180 & 150 \\
CDT-2 & 3 & 4.5 & 30 & 1.5 & 120 & 180 & 150 \\
CDT-3 & 3 & 4.5 & 30 & 1.5 & 180 & 60 & 150 \\
\hline
\end{tabular}

The low temperature detoxification test was repeated for the waste roofing slate. Cement hydrate removal was performed under various experimental conditions (Table 3). After the waste roofing slate and solution were combined, a silicone-based anti-foamer was added to the slurry to reduce froth 
floatation during the early stage of the reaction. The slurry obtained from the slate acid treatment test was centrifuged at $3000 \mathrm{rpm}$ for 5 min using UNION 32R centrifuge machine (Hanil Science Industrial, Gimpo, Korea) to separate the solid. The $\mathrm{pH}$ of the supernatant was immediately measured. The solid was subsequently centrifuged two more times to wash out residual chemicals on the surface of the solid. Solid particles obtained from the centrifuge were oven-dried for $24 \mathrm{~h}$, for subsequent use in the low temperature detoxification test.

Table 3. Experiment conditions of slate acid treatment test.

\begin{tabular}{cc}
\hline Experiment Variables & Experiment Conditions \\
\hline Waste roofing slate $(\mathrm{g})$ & $50,200,400,2000$ \\
$\mathrm{HCl}$ to solid ratio $(\mathrm{g} / \mathrm{g})$ & $0.400 \sim 0.520$ \\
Amount of $\mathrm{HCl}$ solution $(\mathrm{mL})$ & $400 \sim 8000$ \\
Reaction time $(\mathrm{h})$ & $1 \sim 3$ \\
Solid to liquid ratio $(\mathrm{g} / \mathrm{mL})$ & $0.125 \sim 0.250$ \\
\hline
\end{tabular}

A small sample $(<1 \mathrm{~g})$ of solids from each test was collected for XRD analysis and FE-SEM analysis, respectively. The low temperature detoxification test was performed using the intermediate product obtained from the cement hydrates removal test. This was placed in a $500 \mathrm{~mL}$ stainless steel reactor and mixed with oxalic acid solution (Table 4 ). The mixture was heated and the temperature was maintained at around $100{ }^{\circ} \mathrm{C}$ using the heating mantle until fully dried. The mixture was also stirred at $250 \mathrm{rpm}$ until its liquidity diminished due to evaporation. After the detoxification test, solid particles were collected for XRD and FE-SEM analyses, to determine the detoxification of asbestos materials. The XRD analyses were conducted using X'pertMPD machine (Philips Co., Amsterdam, The Netherland) with graphite monochromatized $\mathrm{CuK} \alpha$ radiation. The FE-SEM analysis were conducted using S-4700 (Hitachi, Tokyo, Japan) at a working voltage of $15 \mathrm{keV}$.

Table 4. Experiment condition of low temperature detoxification test.

\begin{tabular}{cccccccc}
\hline No. & $\begin{array}{c}\text { Intermediate } \\
\text { Product }(\mathbf{g})\end{array}$ & $\begin{array}{c}\text { Oxalic } \\
\text { Acid }(\mathbf{g})\end{array}$ & $\begin{array}{c}\text { Water } \\
\mathbf{( m L )}\end{array}$ & $\begin{array}{c}\text { Oxalic Acid } \\
\text { to Solid } \\
\text { Ratio }(\mathbf{g} / \mathbf{g})\end{array}$ & $\begin{array}{c}\text { Reaction } \\
\text { Temperature } \\
\left.\mathbf{(}{ }^{\circ} \mathbf{C}\right)\end{array}$ & $\begin{array}{c}\text { Reaction } \\
\text { Time } \\
(\mathbf{m i n})\end{array}$ & $\begin{array}{c}\text { Mass of } \\
\text { Product } \\
(\mathbf{g})\end{array}$ \\
\hline ADT-1 & 60 & 40 & 120 & 0.67 & 100.5 & 75 & 92.6 \\
ADT-2 & 60 & 43 & 140 & 0.72 & 100.7 & 90 & 90.2 \\
ADT-3 & 60 & 45 & 140 & 0.75 & 100.7 & 100 & 90.2 \\
ADT-4 & 60 & 47 & 140 & 0.78 & 101.3 & 90 & 94.2 \\
ADT-5 & 60 & 50 & 140 & 0.83 & 101.4 & 90 & 97.3 \\
ADT-6 & 90 & 68 & 210 & 0.75 & 101.4 & 135 & 147.1 \\
\hline
\end{tabular}

\section{Results and Discussions}

\subsection{Low Temperature Detoxification Test Using Chrysotile}

Figure 2 shows the XRD analysis results of raw material and solid particles obtained from the low temperature detoxification test using chrysotile. The XRD chart clearly shows that chrysotile peaks in the raw material disappeared after the low temperature detoxification process, and $\mathrm{Mg}$-oxalate could be identified as the main component under all oxalic acid to solid ratio, temperature, and reaction time conditions. Magnetite $\left(\mathrm{Fe}_{3} \mathrm{O}_{4}\right)$ in the chrysotile also disappeared after the process regardless of experimental conditions. However, brucite $(\mathrm{MgOH})$ disappeared only at CDT-1 (oxalic acid to solid ratio: $1.0 \mathrm{~g} / \mathrm{g}$ ). It can be presumed that Fe from dissolved magnetite precipitated with $\mathrm{Mg}$-oxalate as an impurity. In the XRD analysis, no Fe-related minerals were identified. At CDT-2 and 3, the precipitation of hydrogen oxalate hydrate was observed, which may have been induced by the excessive amount of oxalic acid. 


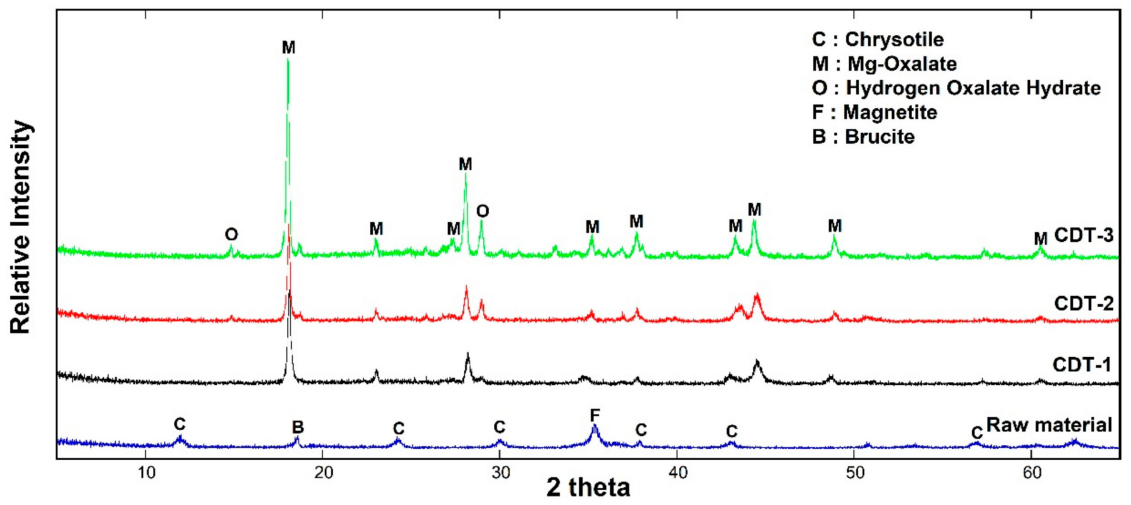

Figure 2. XRD results of raw material and solid samples obtained from low temperature detoxification test using chrysotile (CDT-1, 2, and 3).

$\mathrm{Mg}$-oxalate peaks were found to be affected by oxalic acid to solid ratio and temperature. At the highest oxalic acid to solid ratio and temperature condition (CDT-3), Mg-oxalate peaks were stronger than in CDT-1 and 2. Even though the excess amount of oxalic acid precipitated as hydrogen oxalate hydrates, it can be presumed that CDT-3 is more appropriate for chrysotile detoxification in this study.

The SEM images present clear evidences of the transformation of fibrous chrysotile to rhombic form Mg-oxalate (Figure 3). After the detoxification process, all fibrous chrysotile disappeared and transformed to Mg-oxalate which has particle diameter of approximately 10-20 $\mu \mathrm{m}$, regardless of experimental conditions. The effect of solid to oxalic acid and temperature was not observed in the SEM analysis.
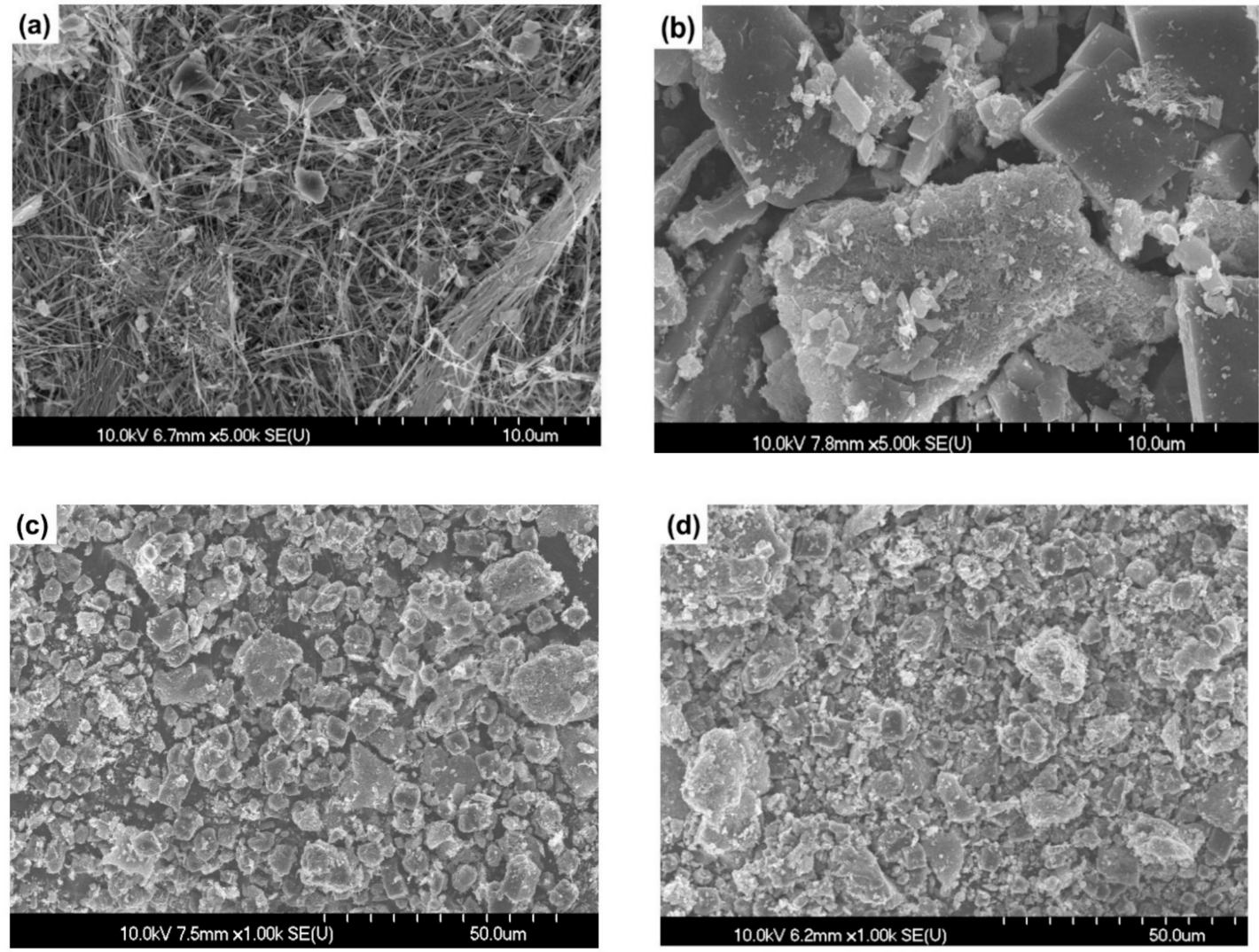

Figure 3. SEM images of solid samples obtained from the low temperature detoxification test using chrysotile: (a) raw material, (b) CDT-1, (c) CDT-2, and (d) CDT-3. 


\subsection{Cement Hydrate Removal Test Using the Waste Roofing Slate}

The amount of remnant after slate acid treatment directly indicates the efficiency of the treatment in dissolving cement hydrates from the raw material. The remnant mass ratio indicates the ratio of the mass of intermediate product and the mass of raw material. Figure 4a shows the remnant mass ratio as a function of reaction time. This did not change noticeably as a function of reaction time at $\mathrm{HCl}$ concentrations of $5.5 \%$ and $5.7 \%$, but decreased as a function of reaction time at $5.0 \%$. The remnant mass ratio was therefore clearly affected by $\mathrm{HCl}$ concentration.

Figure $4 \mathrm{~b}$ shows the remnant mass ratio as a function of $\mathrm{HCl}$ to solid ratio $(\mathrm{g} / \mathrm{g})$, with reaction times of $2 \mathrm{~h}$ and $3 \mathrm{~h}$. Although only three different $\mathrm{HCl}$ dosage tests were conducted with solid dosage of $0.125 \mathrm{~g} / \mathrm{mL}$ over $2 \mathrm{~h}$, it can be presumed that the reaction time was not affected on remnant mass ratio. The ratio was, however, clearly affected by solid to liquid ratio. Lower solid to liquid ratio produced a smaller remnant mass ratio than higher solid to liquid ratio, probably due to a larger portion of aqueous phase in the slurry. Dissolution of solid material can usually be enhanced by increasing the solution to solid ratio. We predict that the trend line (dotted line) of remnant mass ratio as a function of $\mathrm{HCl}$ to solid ratio will probably converge around the asbestos content in waste roofing slate $(13-15 \%)$.

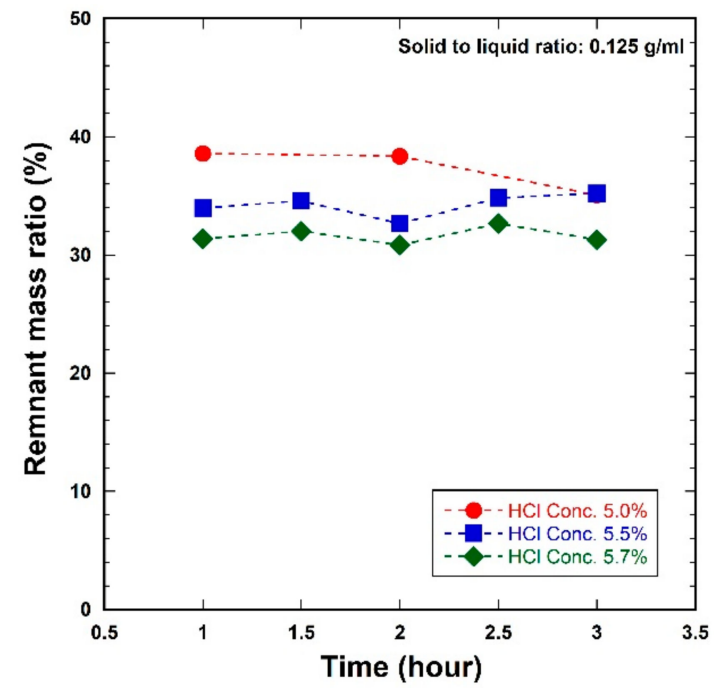

(a)

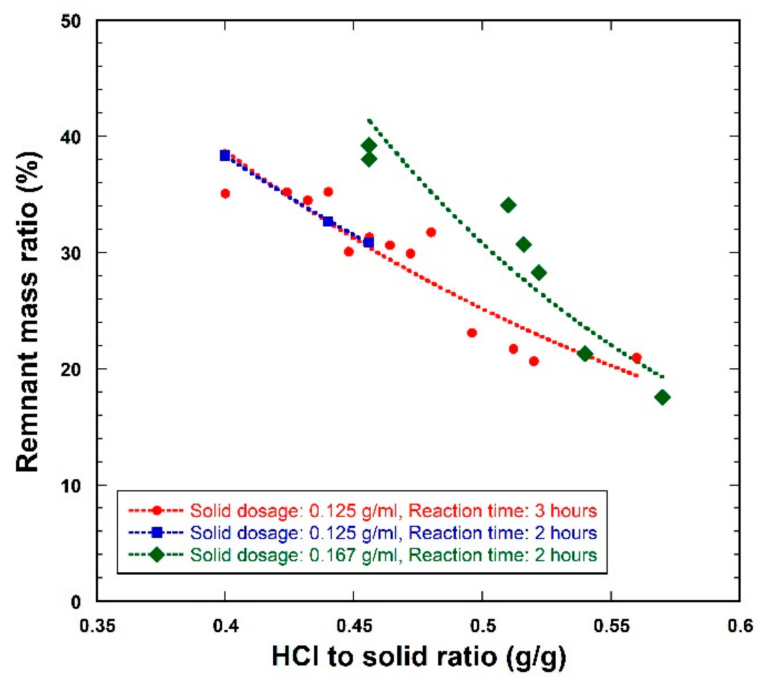

(b)

Figure 4. Remnant mass ratio (a) as a function of reaction time with the $5.0 \%, 5.5 \%$, and $5.7 \% \mathrm{HCl}$ solutions (solid to liquid ratio: $0.125 \mathrm{~g} / \mathrm{mL}$ and $(\mathbf{b})$ as a function of $\mathrm{HCl}$ to solid ratio with reaction times of 2 and 3 hours (dotted lines: trend line of remnant mass ratio as a function of $\mathrm{HCl}$ to solid ratio).

Figure 5 shows XRD analysis results of solid samples obtained from cement hydrate removal tests. The calcite peaks in the raw material disappeared after the reaction under all conditions of $\mathrm{HCl}$ to solid ratio $>0.4 \mathrm{~g} / \mathrm{g}$, regardless of reaction time. It was also observed that remnant weak intensity peaks of calcite were observed at $\mathrm{HCl}$ to solid ratio of $0.4 \mathrm{~g} / \mathrm{g}$ after the reaction. The calcium silicate peaks representing unhydrated cement parts disappeared after the reaction. Hydrochloric acid was able to dissolve both unhydrated calcium silicate and cement hydrates from waste roofing slate. The intensity of chrysotile peaks (mainly at 12) were strengthened after the reaction under all conditions that resulted from dissolution of cement-related components from raw material. The effect of reaction time on dissolution of cement hydrates was not identified in the XRD analysis. Figure 6 shows the effect of $\mathrm{HCl}$ to solid ratio on dissolution of waste roofing slate. As expected, stronger chrysotile peaks were observed at higher $\mathrm{HCl}$ to solid ratio. 

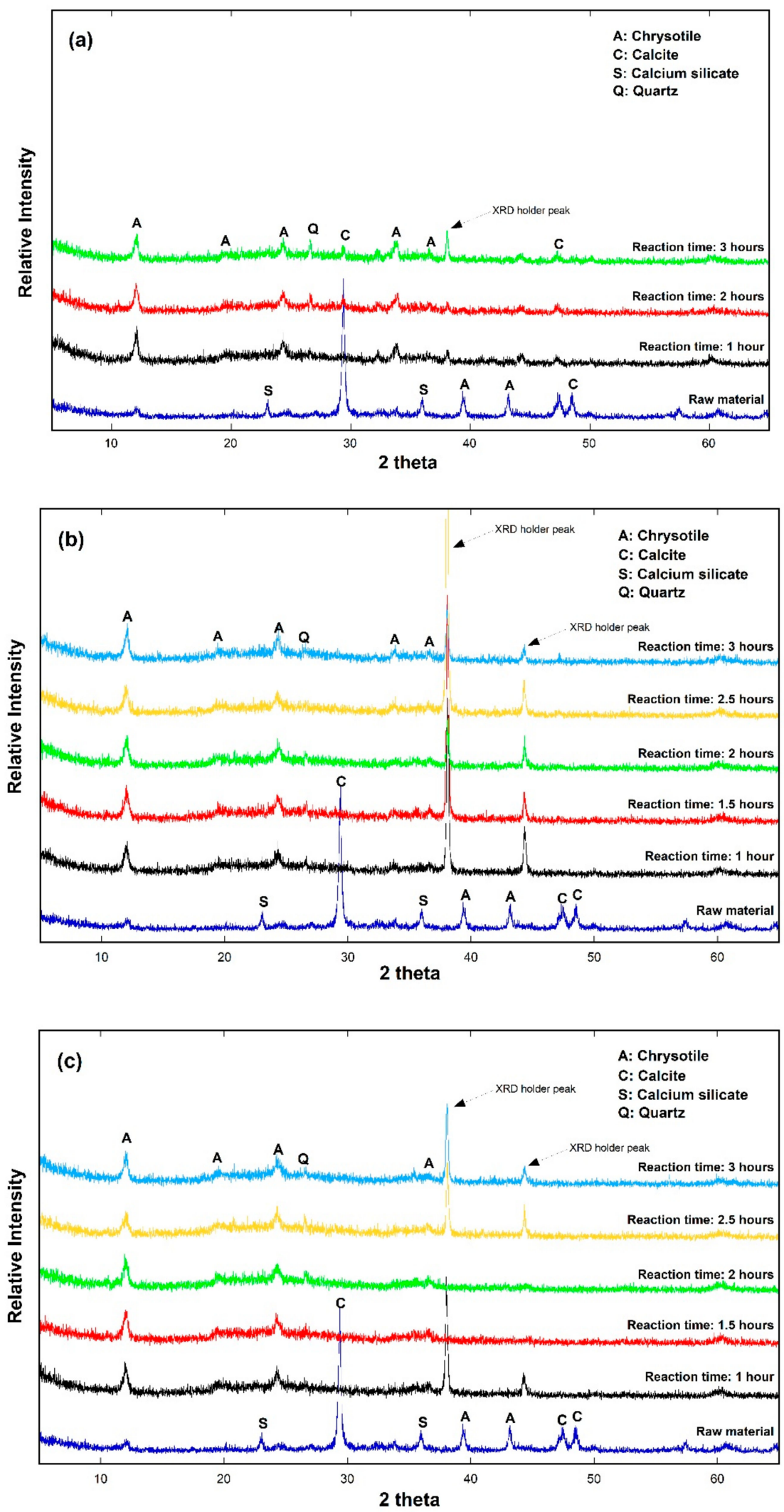

Figure 5. XRD results of solid samples obtained from cement hydrate removal tests (peaks at 39 and 44 are specimen holder). (a) $\mathrm{HCl}$ to solid ratio $0.400 \mathrm{~g} / \mathrm{g}$ (b) $\mathrm{HCl}$ to solid ratio $0.440 \mathrm{~g} / \mathrm{g}$, and (c) $\mathrm{HCl}$ to solid ratio $0.456 \mathrm{~g} / \mathrm{g}$. 


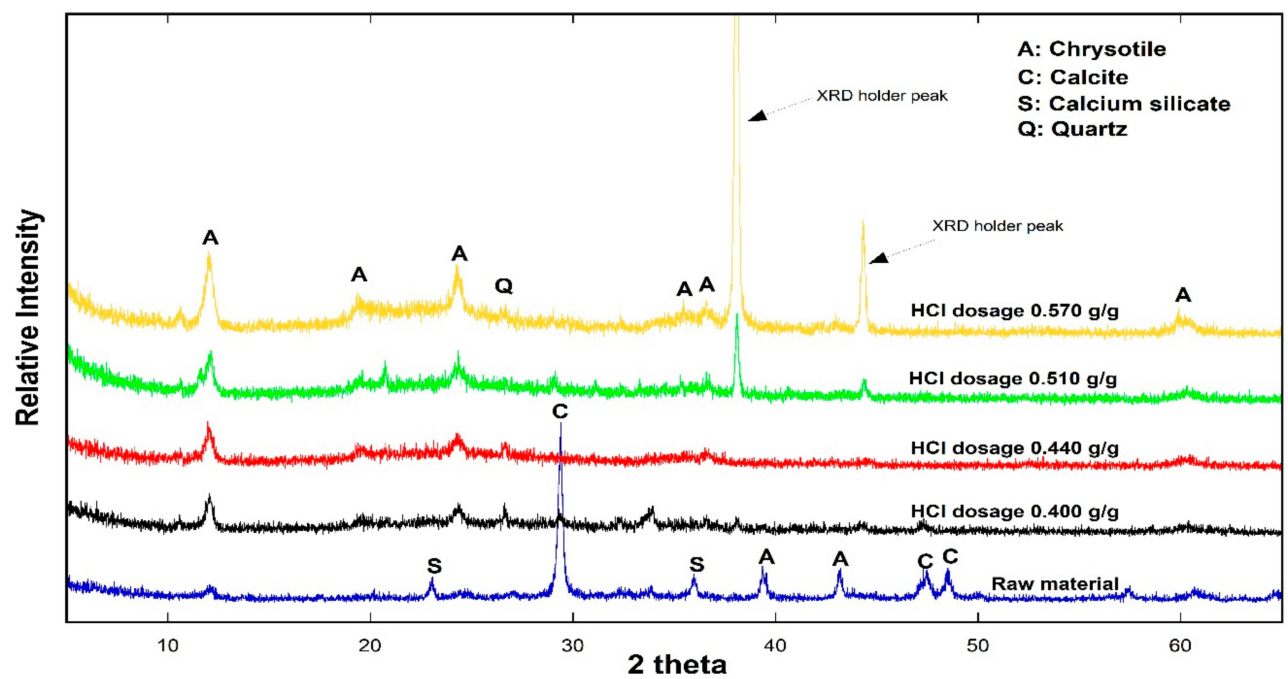

Figure 6. XRD results of solid samples obtained from cement hydrate removal tests at different $\mathrm{HCl}$ to solid ratio (peaks at 39 and 44 represent specimen holder).

Morphological alteration of waste roofing slate was observed using SEM analysis on waste roofing slate and solid samples obtained following the cement hydrate removal test using $\mathrm{HCl}$ 5.7\% ( $\mathrm{HCl}$ to solid ratio: $0.456 \mathrm{~g} / \mathrm{g}$ ) (Figure 7). Bunches of elongated fibrous asbestos mixed with cement hydrates were observed in the raw material. In the solid samples obtained following cement hydrate removal, however, mostly spheroidal-shaped particles and fibrous asbestos could be observed. In the detailed view, spheroidal-shaped particles were revealed as conglomerates of $\mu \mathrm{m}$-scale fibrous materials (Figure 7c,d). It is presumed that the spheroidal-shaped conglomerates were formed by flocculation of chrysotile due to the very low $\mathrm{pH}$ of the solution during the test. Silicate minerals, including chrysotile, can be flocculated at $\mathrm{pH}$ lower than their isoelectric point [19]. Despite a large portion of chrysotile being shortened and flocculated during the cement hydrates removal test, this still retained a fibrous form and could be scattered into the atmosphere. Additional treatment of $\mathrm{HCl}$-treated waste roofing slate is therefore essential for asbestos detoxification.

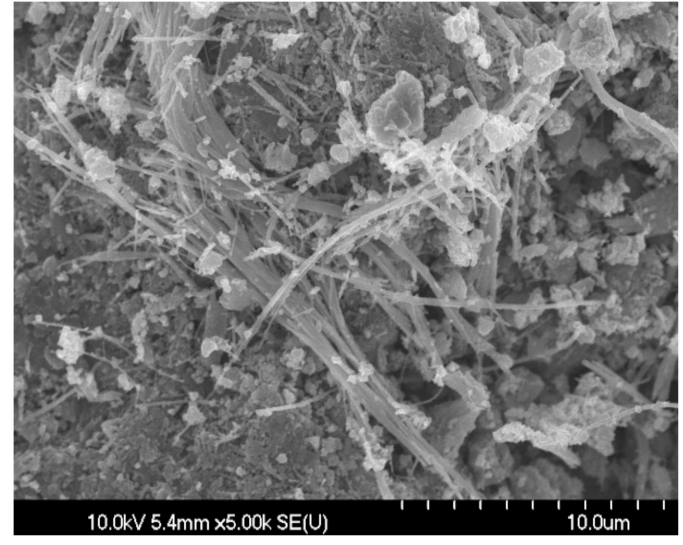

(a)

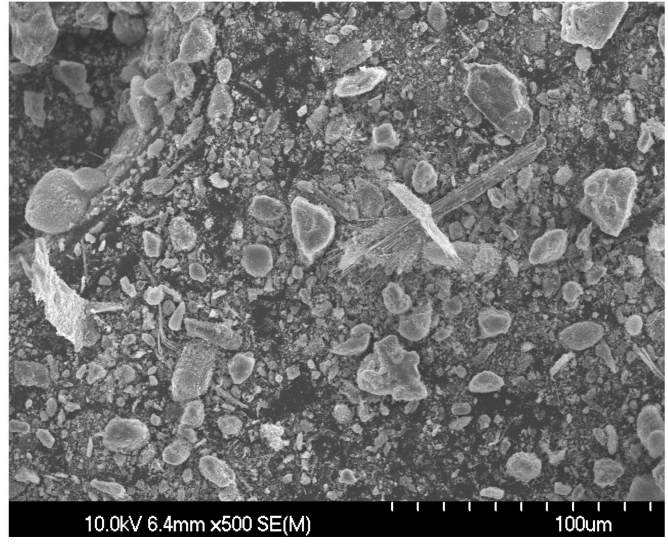

(b)

Figure 7. Cont. 


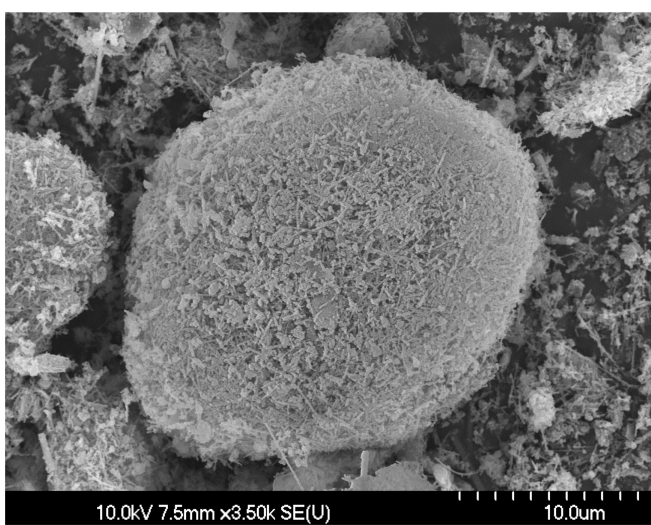

(c)

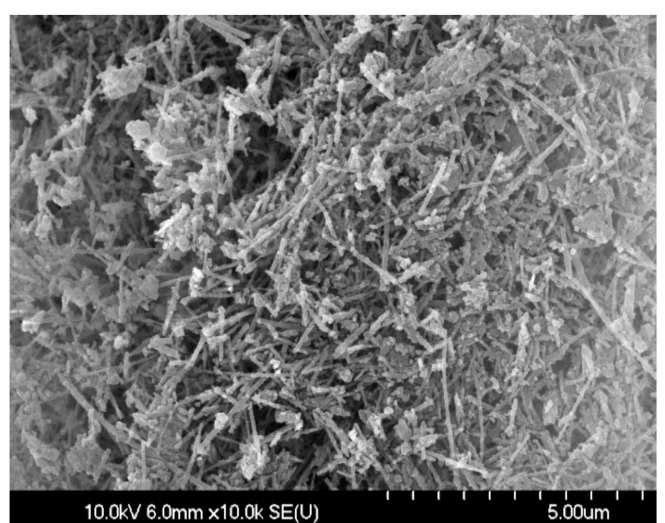

(d)

Figure 7. SEM images of waste roofing slate raw material (a) and solid samples obtained from cement hydrates removal test using $\mathrm{HCl}$ to solid ratio $0.456 \mathrm{~g} / \mathrm{g}(\mathbf{b}-\mathbf{d})$.

\subsection{Low Temperature Detoxification Test Using the Waste Roofing Slate}

The low temperature detoxification test was conducted with oxalic acid on the intermediate product obtained from the cement hydrates removal test under the following conditions: $\mathrm{HCl}$ to solid ratio: $0.456 \mathrm{~g} / \mathrm{g}$, reaction time: $2 \mathrm{~h}$, and solid to liquid ratio: $0.125 \mathrm{~g} / \mathrm{mL}$. After low temperature detoxification, chrysotile peaks disappeared from XRD charts under all conditions (Figure 8); instead, we mainly identified Mg-oxalate $\left(\mathrm{MgC}_{2} \mathrm{O}_{4}\right)$ and Ca-oxalate $\left(\mathrm{CaC}_{2} \mathrm{O}_{4}\right)$. It is believed that the following chemical reactions occurred simultaneously during the low temperature detoxification test:

$$
\begin{gathered}
\mathrm{Mg}_{3} \mathrm{Si}_{2} \mathrm{O}_{5}(\mathrm{OH})_{4}+3 \mathrm{H}_{2} \mathrm{C}_{2} \mathrm{O}_{4} \cdot 2 \mathrm{H}_{2} \mathrm{O} \rightarrow 3 \mathrm{MgC}_{2} \mathrm{O}_{4}+2 \mathrm{SiO}_{2}+5 \mathrm{H}_{2} \mathrm{O} \\
3 \mathrm{CaCl}_{2}+3 \mathrm{H}_{2} \mathrm{C}_{2} \mathrm{O}_{4} \rightarrow 3 \mathrm{CaC}_{2} \mathrm{O}_{4}+6 \mathrm{HCl}
\end{gathered}
$$

Chrysotile $\left(\mathrm{Mg}_{3} \mathrm{Si}_{2} \mathrm{O}_{5}(\mathrm{OH})_{4}\right)$ in the intermediate product reacts with oxalic acid to form Mg-oxalate, a non-hazardous material with cubic or rhombohedral form.

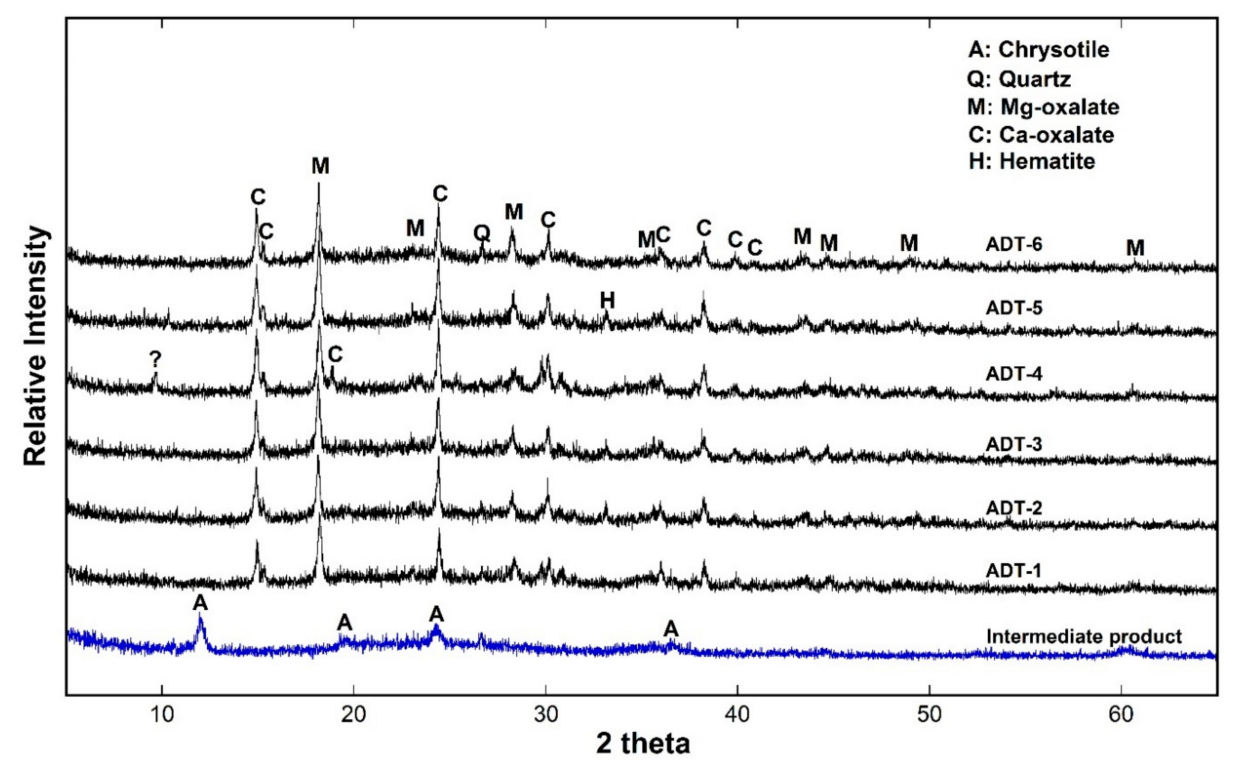

Figure 8. XRD results of the low temperature detoxification tests. Intermediate product indicates the solid sample obtained from the cement hydrates removal test at the conditions of $\mathrm{HCl}$ to solid ratio: $0.456 \mathrm{~g} / \mathrm{g}$, reaction time: $2 \mathrm{~h}$, and solid to liquid ratio: $0.124 \mathrm{~g} / \mathrm{mL}$. 
It is believed that Ca-oxalate in the product of the low temperature detoxification test is induced by a reaction between $\mathrm{CaCl}_{2}$ and oxalic acid. Despite centrifuging and oven drying of the intermediate product, $\mathrm{CaCl}_{2}$ was still present. We calculated that $3 \mathrm{~mol}$ of oxalic acid are needed to transform $1 \mathrm{~mol}$ of chrysotile, meaning that about $1.36 \mathrm{~g}$ of oxalic acid would be needed to transform $1 \mathrm{~g}$ of chrysotile into $\mathrm{Mg}$-oxalate. In this low temperature detoxification treatment, $0.67-0.83 \mathrm{~g}$ of oxalic acid were used per $1 \mathrm{~g}$ of intermediate product. However, waste roofing slate raw material contains about $15 \%$ chrysotile. The remnant mass ratio after cement hydrate removal was $20 \%-40 \%$, depending on $\mathrm{HCl}$ to solid ratio. The remnant mass ratio of intermediate product used in the low temperature detoxification test was $\sim 30 \%$, meaning that $30 \mathrm{~g}$ and $45 \mathrm{~g}$ of chrysotile were respectively present in the $60 \mathrm{~g}$ and $90 \mathrm{~g}$ solid samples obtained from the cement hydrates removal test. As an example, approximately $41 \mathrm{~g}$ of oxalic acid would be needed to transform chrysotile to Mg-oxalate for $60 \mathrm{~g}$ of solid sample. It can be presumed that $5 \mathrm{~g}$ and $10 \mathrm{~g}$ of excess oxalic acid induced formation of Ca oxalate $\left(\mathrm{CaC}_{2} \mathrm{O} 4\right)$ and hydrogen oxalate $\left(\mathrm{H}_{2} \mathrm{C}_{2} \mathrm{O}_{4}\right)$. Hematite $\left(\mathrm{Fe}_{2} \mathrm{O}_{3}\right)$ peaks were identified at ADT-2, 3, and 5. It is believed that Fe content in the raw material (3.6\%) precipitated in hematite form which was not observed in the experiment using chrysotile. Additionally, a peak of an unidentified mineral was observed at $\sim 10^{\circ}$ from ADT-4, but this is not relevant to chrysotile.

The SEM images of the final product obtained following low temperature detoxification show that the two-step treatment (cement hydrates removal and low temperature detoxification) proposed in this study effectively modified the fibrous morphology of chrysotile into a low crystallinity cubic form of $\mathrm{Mg}$-oxalate $\left(\mathrm{MgC}_{2} \mathrm{O}_{4}\right)$ (Figure 9). After low temperature detoxification, fibrous chrysotile was transformed to $\mathrm{Mg}$-oxalate. The morphology of $\mathrm{Mg}$-oxalate was not affected by low temperature detoxification test conditions. Mg-oxalate had an irregular shape regardless of test conditions; this may be induced by the complex chemistry of intermediate products.

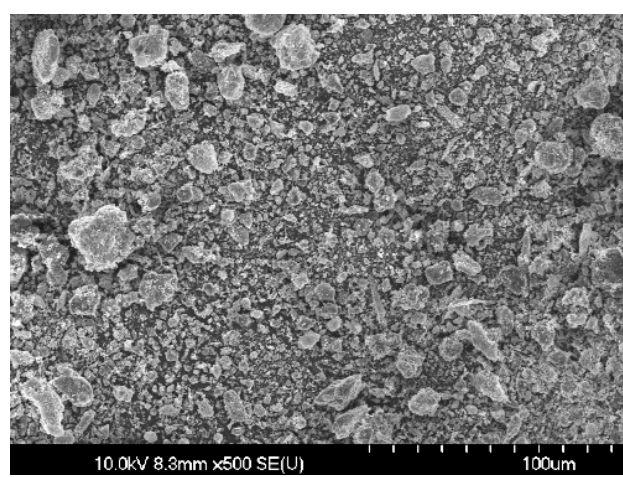

(a)

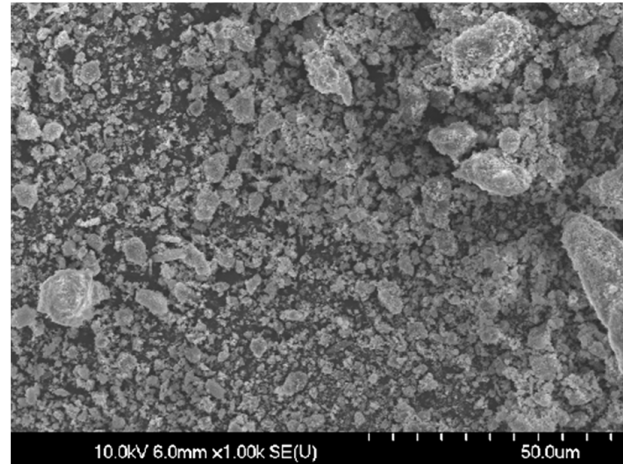

(c)

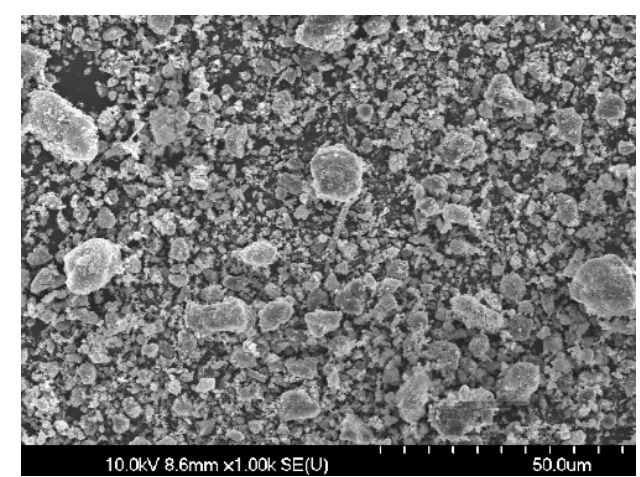

(b)

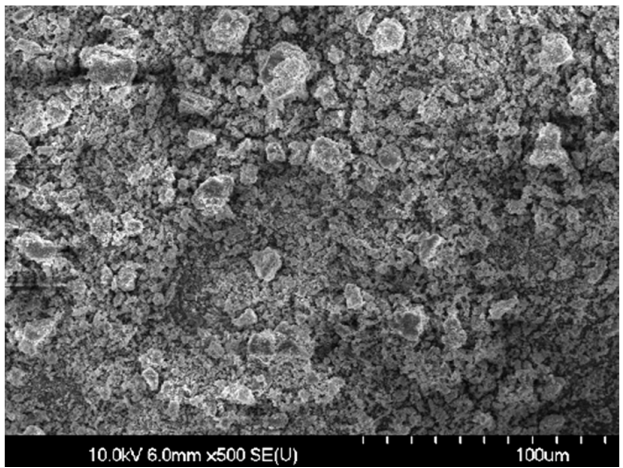

(d)

Figure 9. Cont. 


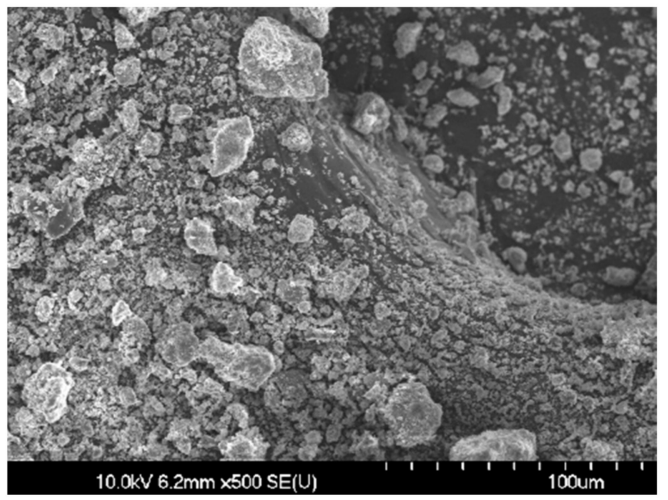

(e)

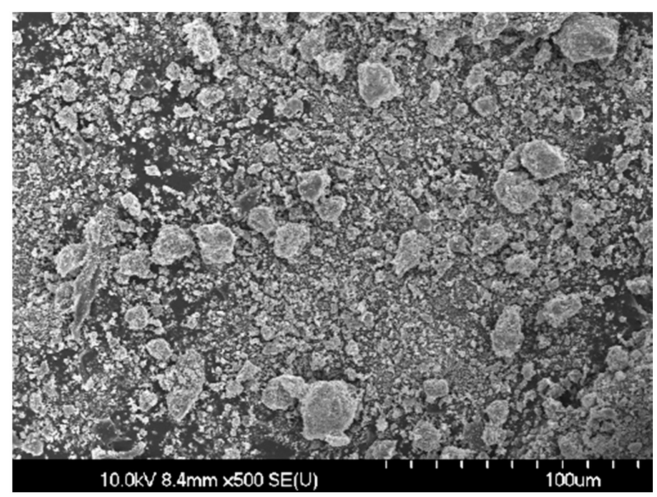

(g)

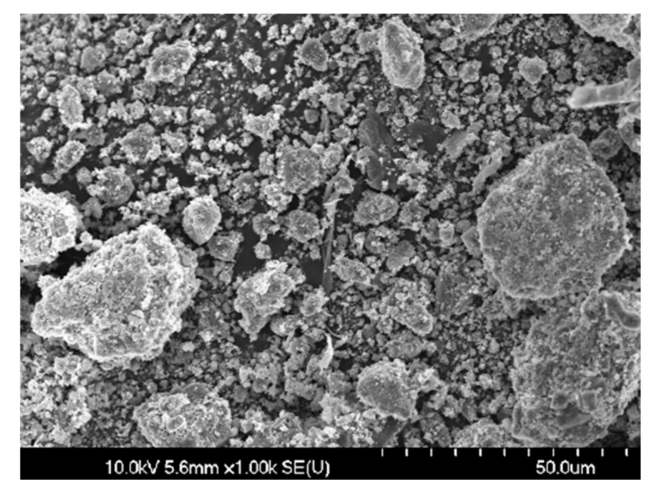

(i)

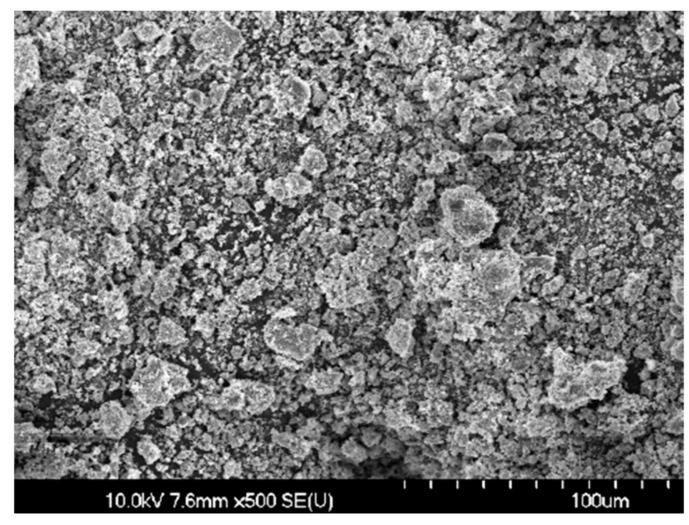

(k)

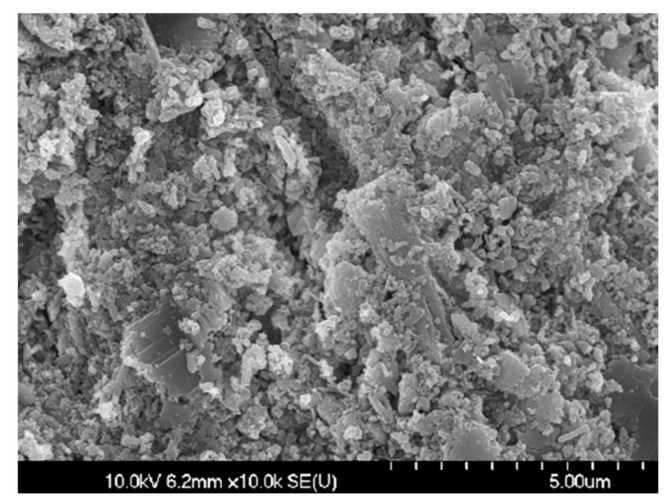

(f)

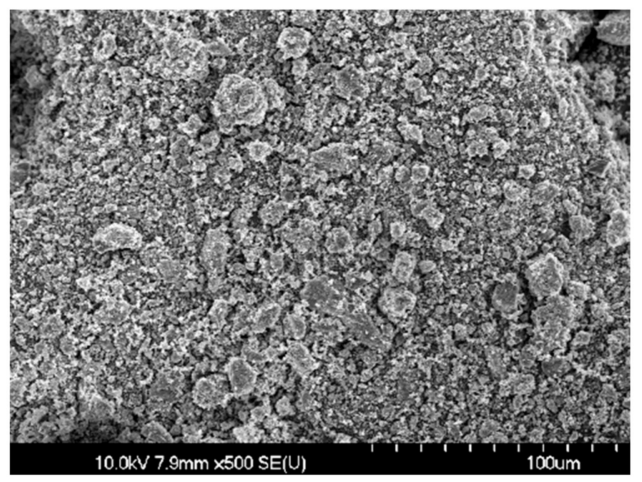

(h)

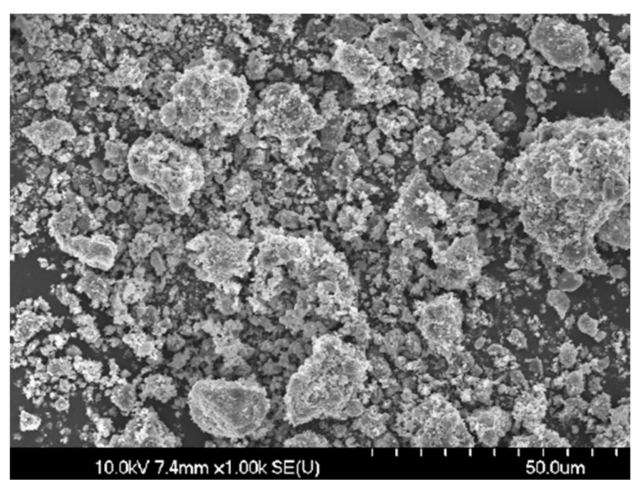

(j)

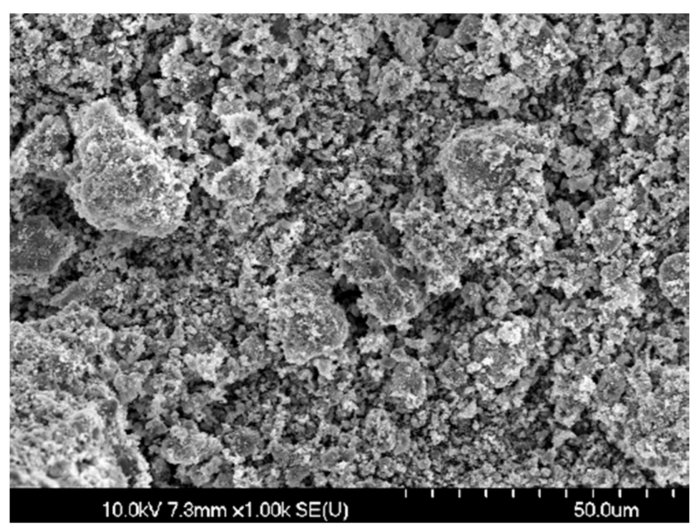

(1)

Figure 9. SEM images of final products from low temperature detoxification test. (a) ADT-1, (b) ADT-1, (c) ADT-2, (d) ADT-2, (e) ADT-3, (f) ADT-4, (g) ADT-4, (h) ADT-4, (i) ADT-5, (j) ADT-5, (k) ADT-6, (1) ADT-6. 


\section{Energy Consumption}

In order to determine the efficiency of the proposed waste roofing slate detoxification method, a simple economic feasibility analysis was conducted. Energy consumption was estimated based on 300 tons/year scale waste roofing slate detoxification facility. Only electricity was considered as a source of energy for stirring, centrifugation, and heating for detoxification. It is calculated that the 300 tons/year scale facility spends approximately $28.3 \mathrm{kWh}$ of electric power per 1 ton of waste roofing slate. The price of electricity was estimated at $0.06 \mathrm{USD} / \mathrm{kWh}$ based on price of industrial electricity in Rep. of Korea. The price of hydrochloric acid and oxalic acid are estimated at 103 and $803.78 \mathrm{USD} / \mathrm{ton}$. It is concluded that the proposed method's operating cost is estimated at 188.07 USD/ton of waste roofing slate which is much cheaper than previous asbestos detoxification method

\section{Conclusions}

In this study, we conducted detoxification of chrysotile and waste asbestos-containing roofing slate using a two-step low temperature detoxification treatment (cement hydrate removal and low temperature detoxification). The low temperature detoxification test using chrysotile clearly showed the effectiveness of the proposed process. The cement hydrate removal test $(\mathrm{HCl}$ to solid ratio: $0.456 \mathrm{~g} / \mathrm{g}$, reaction time: $2 \mathrm{~h}$, and solid to liquid ratio: $0.124 \mathrm{~g} / \mathrm{mL}$ ) effectively eliminated cement hydrate components from waste roofing slate that showed by disappearance of calcium silicate peaks and calcium carbonation peaks after the treatment. Low temperature detoxification (oxalic acid to solid ratio: 0.72 , reaction temperature: $100.7^{\circ} \mathrm{C}$, and reaction time: $90 \mathrm{~min}$ ) effectively transformed chrysotile to non-toxic Mg-oxalate that showed by XRD analyses and SEM images. Ca content after cement hydrate removal was an efficiency-limiting factor due to the fact that is has higher reactivity than Mg. The results of the study suggest that this two-step treatment can effectively transforms the fibrous chrysotile into magnesium oxalate. It can also provide a chance to reused waste roofing slate waste to $\mathrm{Mg}$ source for other industrial field. The Magnesium oxalate can be decomposed to $\mathrm{MgO}$ at the temperature of $400{ }^{\circ} \mathrm{C}$ [20]. Simplified efficiency analysis on proposed method result showed that approximately 188.07 USD is needed to treat 1 ton of waste roofing slate. A pilot-scale waste roofing slate treatment process should be conducted to confirm potential commercial applicability.

Acknowledgments: This work was supported by the Basic Research Project (GP2015-022) of the Korea Institute of Geoscience and Mineral Resources (KIGAM) funded by the Ministry of Science and ICT, Rep. of Korea.

Author Contributions: Young Nam Jang and Hwanju Jo conceived and designed the experiments; Hwanju Jo and Jung Hyun Jo performed the experiments; Young Nam Jang and Hwanju Jo analyzed the data.

Conflicts of Interest: The authors declare no conflict of interest.

\section{References}

1. Bianchi, C.; Bianchi, T. Asbestos between science and myth. A 6000-year story. Med. Lav. 2015, 106, 83-90. [PubMed]

2. Kusiorowski, R.; Zaremba, T.; Gerle, A.; Piotrowski, J.; Simka, W.; Adamek, J. Study on the thermal decomposition of crocidolite asbestos. J. Therm. Anal. Calorim. 2015, 120, 1585-1595. [CrossRef]

3. Institute of Medicine (US) Committee on Asbestos: Selected Health Effects. Asbestos: Selected Cancers; National Academies Press (US): Washington, DC, USA, 2006; pp. 1-327.

4. World Health Organization. Chrysotile Asbestos; World Health Organization: Geneva, Switzerland, 2014.

5. Choi, J.K.; Paek, D.M.; Paik, N.W. The production, the use, the number of workers and exposure level of asbestos in Korea. J. Korean Soc. Occup. Environ. Hyg. 1998, 8, 242-253.

6. Gualtieri, A.F.; Tartaglia, A. Thermal decomposition of asbestos and recycling in traditional ceramics. J. Eur. Ceram. Soc. 2000, 20, 1409-1418. [CrossRef]

7. Kozawa, T.; Onda, A.; Yanagisawa, K.; Chiba, O.; Ishiwata, H.; Takanami, T. Thermal decomposition of chrysotile-containing wastes in a water vapor atmosphere. J. Ceram. Soc. Jpn. 2010, 118, 1199-1201. [CrossRef] 
8. Yoshikawa, N.; Kashimura, K.; Hashiguchi, M.; Sato, M.; Horikoshi, S.; Mitani, T.; Shinohara, N. Detoxification mechanism of asbestos materials by microwave treatment. J. Hazard. Mater. 2015, 284, 201-206. [CrossRef] [PubMed]

9. Leonelli, C.; Veronesi, P.; Boccaccini, D.N.; Rivasi, M.R.; Barbieri, L.; Andreola, F.; Lancellotti, I.; Rabitti, D.; Pellacani, G.C. Microwave thermal inertisation of asbestos containing waste and its recycling in traditional ceramics. J. Hazard. Mater. 2006, 135, 149-155. [CrossRef] [PubMed]

10. Horikoshi, S.; Sumi, T.; Ito, S.; Dillert, R.; Kashimura, K.; Yoshikawa, N.; Sato, M.; Shinohara, N. Microwave-driven asbestos treatment and its scale-up for use after natural disasters. Environ. Sci. Technol. 2014, 48, 6882-6890. [CrossRef] [PubMed]

11. Averroes, A.; Sekiguchi, H.; Sakamoto, K. Treatment of airborne asbestos and asbestos-like microfiber particles using atmospheric microwave air plasma. J. Hazard. Mater. 2011, 195, 405-413. [CrossRef] [PubMed]

12. Nam, S.-N.; Jeong, S.; Lim, H. Thermochemical destruction of asbestos-containing roofing slate and the feasibility of using recycled waste sulfuric acid. J. Hazard. Mater. 2014, 265, 151-157. [CrossRef] [PubMed]

13. Sugama, T.; Sabatini, R.; Petrakis, L. Decomposition of chrysotile asbestos by fluorosulfonic acid. Ind. Eng. Chem. Res. 1998, 37, 79-88. [CrossRef]

14. Yanagisawa, K.; Kozawa, T.; Onda, A.; Kanazawa, M.; Shinohara, J.; Takanami, T.; Shiraishi, M. A novel decomposition technique of friable asbestos by $\mathrm{CHClF}_{2}$-decomposed acidic gas. J. Hazard. Mater. 2009, 163, 593-599. [CrossRef] [PubMed]

15. Tabata, M.; Shono, A.; Ghaffar, A. Decomposition of asbestos by a supernatant used for immobilization of heavy metals in fly ash. J. Mater. Cycles Waste Manag. 2016, 18, 483-492. [CrossRef]

16. Turci, F.; Tomatis, M.; Mantegna, S.; Cravotto, G.; Fubini, B. The combination of oxalic acid with power ultrasound fully degrades chrysotile asbestos fibres. J. Environ. Monit. 2007, 9, 1064-1066. [CrossRef] [PubMed]

17. Rozalen, M.; Huertas, F.J. Comparative effect of chrysotile leaching in nitric, sulfuric and oxalic acids at room temperature. Chem. Geol. 2013, 352, 134-142. [CrossRef]

18. Valouma, A.; Verganelaki, A.; Maravelaki-Kalaitzaki, P.; Gidarakos, E. Chrysotile asbestos detoxification with a combined treatment of oxalic acid and silicates producing amorphous silica and biomaterial. J. Hazard. Mater. 2016, 305, 164-170. [CrossRef] [PubMed]

19. Harada, T.; Owada, S.; Sugiyama, N. The effect of hcl treatment on zeta-potential, flocculation dispersion characteristics and floatability of silicate minerals. Shigen-to-Sozai 1989, 105, 1059-1065. [CrossRef]

20. Mohandes, F.; Davar, F.; Salavati-Niasari, M. Magnesium oxide nanocrystals via thermal decomposition of magnesium oxalate. J. Phys. Chem. Solids 2010, 71, 1623-1628. [CrossRef] 